Published in: Corpora 11 (2016), No. 2, pp. 259-290

\title{
POSTPRINT
}

\section{Frames, polarity and causation}

\author{
Josef Ruppenhofer ${ }^{1}$ and Laura A. Michaelis ${ }^{2}$
}

\begin{abstract}
A polarity-sensitive item (PSI), as traditionally defined, is an expression that is restricted to either an affirmative or negative context. PSIs like 'lift a finger' and 'all the time in the world' sub-serve discourse routines like understatement and emphasis. Lexical-semantic classes are increasingly invoked in descriptions of the properties of PSIs. Here, we use English corpus data and the tools of Frame Semantics (Fillmore, 1982, 1985) to explore Israel's (2011) observation that the semantic role of a PSI determines how the expression fits into a contextually constructed scalar model. We focus on a class of exceptions implied by Israel's model: cases in which a given PSI displays two countervailing patterns of polarity sensitivity, with attendant differences in scalar entailments. We offer a set of case studies of polaritysensitive expressions - including verbs of attraction and aversion like 'can live without', monetary units like 'a red cent', comparative adjectives and time-span adverbials - that demonstrate that the interpretation of a given PSI in a given polar context is based on multiple factors. These factors include the speaker's perspective on and affective stance towards the described event, available inferences about causality and, perhaps most critically, particulars of the predication, including the verb or adjective's frame membership, the presence or absence of an ability modal like can, the grammatical construction used and the range of contingencies evoked by the utterance.
\end{abstract}

Keywords: Frame semantics, polarity sensitive items, scalar rhetoric, sentiment analysis.

\section{Introduction}

This study examines a class of little words with big rhetorical import: polarity-sensitive items (PSIs). A PSI is an expression that is restricted to

\footnotetext{
${ }^{1}$ Leibniz Science Campus, Institute for German Language, R5 6-13, 68161 Mannheim, Germany.

${ }^{2}$ Department of Linguistics, 295UCB, University of Colorado, Boulder, CO 80309, USA.

Correspondence to: Josef Ruppenhofer, e-mail: ruppenhofer@ids-mannheim.de
} 
a particular kind of linguistic act. While PSIs sub-serve discourse stancerelated routines like understatement and emphasis, they are amenable to lexical-semantic analysis. We focus on frame-semantic properties of PSIs and ask how they are related to the writer's communicative intent. PSIs constitute a heterogeneous class of expressions, comprising nominals like the first thing, adverbs like ever and at all, weak quantifiers like some and few, verbs like budge and intensifiers like as hell and totally. PSIs are a class defined by their contextual restrictions. Some PSIs, the socalled positive polarity items (PPIs), are confined to reports of actual or anticipated situations (e.g., 'It's (gonna be) hot as hell'). Other PSIs, which the literature misleadingly refers to as 'negative polarity items' (NPIs), occur only in linguistic acts that evoke a range of potential outcomes-whether these outcomes are an array of things that failed to happen ('She didn't ever say a word'), multiple standards of comparison ('It's better than ever'), possible values of a given variable, as in yes-no questions ('Do you ever talk?'), or various contingencies, as in conditional sentences ('If you ever need anything...'). Among PSIs, NPIs like $a$ red cent and lift a finger have received the most attention, both from linguistic theorists (among others, Israel, 1996, 2011; Krifka, 1995; Hoeksema and Rullmann, 2001; and van der Wouden, 1994) and computational linguists (e.g., Fritzinger et al., 2010; and Lichte and Soehn, 2007). Theorists have focussed on enumerating the structural and discourse contexts in which NPIs are licenced and the role of NPIs in scalar reasoning. Computational linguists have focussed on acquiring items that are candidates for NPI status.

Following Israel (1996), we view NPIs as inviting scalar inferences, by virtue of their lexical-semantic meanings. The contention that NPIs necessarily evoke scales is not uncontroversial. Giannakidou (2012), among others, has argued that a scalar approach to NPI meaning provides a weak account of NPI use in non-veridical (e.g., modal, question and propositional attitude) contexts in general and falsely predicts that 'illicit NPIs are merely uninformative or contradictory, when, in fact, they are ungrammatical' (p. 1705). While we concede that scalar NPIs may be a sub-set of a more general class of NPIs, we focus our attention on the connection between lexical semantics and scalar rhetoric, and thus on those NPIs that are obviously amenable to a scalar analysis. An illustration of this connection is found in the following song lyric:

You said you were in love with me

Both of us know that that's impossible

And I could make you rue the day

But I could never make you stay

Not for all the tea in China

Not if I could sing like a bird

Not for all North Carolina

Not for all my little words

(All My Little Words, The Magnetic Fields) 
This passage suggests that while PSIs, and in particular the NPI 'for all the tea in China', have rhetorical effects, they are not needed to generate these effects. A reader can easily construe the second verse as a series of emphatic denials of the sufficiency of some remuneration. These denials count as emphatic because of what they entail: if the speaker is unwilling to perform a certain act in exchange for very high remuneration, then he is extremely unwilling to perform that act. Crucially, however, this inference pattern is not tied to the presence of a conventionalised PSI: the ability to sing like a bird, the state of North Carolina and words are not commodities - much less traditional forms of remuneration. Thus, detecting the invited inference is of interest whether or not it is triggered by a conventional PSI; the reasoning patterns associated with PSIs exist independently of PSIs, emerging from semantic roles and relations that PSIs denote.

In brief, polarity sensitivity is not an arbitrary grammatical phenomenon: PSIs are a semantically unified class. In this contribution, we explore Israel's 2011 claim that the patterns of scalar reasoning evoked by PSIs arise from the lexical classes to which they belong and, in many instances, the semantic roles that they fill (see Section 2). Israel's proposal is of great interest because it would, if substantiated, enable us to leverage frame-semantic information in searching for candidate PSIs, and thus identify PSIs and instances of scalar rhetoric in a more targeted fashion than has thus far been possible.

We take Israel's (2011) four-dimensional taxonomy of PSIs as our point of departure, as well as his account of the semantic conditions that give rise to 'inverted' PSIs: those whose contextual restrictions are not predicted by taxonomic class. What is newsworthy in this study is the identification of 'bipolar PSIs': those that exhibit both inverted and canonical behaviours. Overall, we find that what makes a PSI a PSI is its sentential context. This study proceeds inductively: we investigate several classes of PSIs in corpora and analyse the instances retrieved using the semantic frame and role inventories defined by the FrameNet project (Baker et al., 1998), a lexical resource based on the theory of Frame Semantics (Fillmore, 1982, 1985) and described in Section 3. In Section 4, we suggest that by aligning sets of predicative PSIs, as identified by Israel, with FrameNet frames, we can (a) recognise further structure in those sets, and $(b)$ identify additional items to add to the sets. In Section 5 , we examine a range of PSIs that denote monetary units; while our findings substantiate Israel's predictions concerning the role of causal inference in polarity inversion, we observe that the construal of a given monetary-unit expression as, for example, an asset, an earning or a tool of persuasion, is dependent on frame-semantic properties of the verb with which it combines. We extend the frame-based approach to the 'constructional' roles of comparative constructions and show that certain role fillers produce certain scalar effects (Section 6). In addition, we discuss grammatical influences on occurrences of PSIs (Section 7). Finally, we situate this work relative to other corpus-based studies of PSIs (Section 8) before offering our conclusions (Section 9). 


\section{Types of polarity-sensitive items}

Our study builds on Israel's (2011) theory of PSIs, which we outline in this section. As noted earlier, PSIs constitute a class of expressions that can appear only in sentential contexts of a particular type: veridical ('positive') or non-veridical contexts. Non-veridical contexts include negative contexts as well as, for example, interrogatives and the antecedents of conditional sentences. We focus on negative contexts rather than the broader class of non-veridical contexts to simplify the description of entailment patterns. Negative contexts are those in which the speaker notes the failure of some expected situation to occur. Such contexts have a variety of formal hallmarks, including verbs like deny, adverbs like rarely, prepositions like without and negative adverbs and morphemes (no, never, etc.). As an example of a canonical PSI, consider the verb-phrase idiom 'lift a finger', which strongly prefers negative contexts:

(I) There are so many ways consumers can earn free cash without having to lift a finger...

(2) \#Most people contributed a lot of effort but Peter only lifted a finger.

Following Israel (1996), we assume four types of PSIs, shown in Table 1. The binary features 'emphatic/attenuating' and 'minimising/maximising' combine to produce two types of NPIs and two types of PPIs. The feature $\pm \mathrm{q}$ refers to the scalar degree (the quantity expressed): a value of $+\mathrm{q}$ reflects a value that is close to the scalar endpoint. The feature $\pm i$ refers to the information value of the resulting predication-whether it entails upward relative to a scale in negative contexts and downward in affirmative contexts. Thus, an emphatic sentence generates a cascade of entailments; for example, someone lacking a penny lacks a dime, a dollar, etc. An attenuating sentence, by contrast, merely invites an inference through an obscure formulation; for example, someone who denies being a 'huge fan' of cream cheese may in fact dislike it.

The taxonomy in Table 1 captures the intuition that expressions which become PSIs, irrespective of polar context, express either minimal or maximal attainment. For instance, a 'wink' is a minimal unit of sleep, as in Example 3, while 'a bit' is a minimal unit of substance (Example 4). By contrast, the attribute 'made of money' in Example 5 denotes extreme wealth while 'as big as all outdoors' in Example 6 denotes extreme size:

(3) She didn't sleep a wink last night. $(-q)$

(4) I had a bit of lunch. (-q)

(5) We are not made of money and price was our number one concern. $(+q)$

(6) It's as big as all outdoors. $(+q)$ 


\begin{tabular}{|l||l|l|l|}
\hline Features & Polarity & $\begin{array}{l}\text { Quantity, } \\
\text { informative- } \\
\text { ness values }\end{array}$ & Example \\
\hline \hline emphatic, minimising & NPI & $-\mathrm{q},+\mathrm{i}$ & $\begin{array}{l}\text { 'budge an inch', 'sleep } \\
\text { a wink', 'at all' }\end{array}$ \\
\cline { 2 - 4 } emphatic, maximising & PPI & $+\mathrm{q},+\mathrm{i}$ & $\begin{array}{l}\text { 'tons', 'utterly', } \\
\text { 'awfully' }\end{array}$ \\
\hline attenuating, minimising & PPI & $-\mathrm{q},-\mathrm{i}$ & $\begin{array}{l}\text { 'sorta', 'somewhat', 'a } \\
\text { little bit' }\end{array}$ \\
\cline { 2 - 4 } attenuating, maximising & NPI & $+\mathrm{q},-\mathrm{i}$ & $\begin{array}{l}\text { 'all that', 'much', } \\
\text { 'long' }\end{array}$ \\
\hline
\end{tabular}

Table 1: Overview of canonical PSI types.

As Table 1 suggests, the combination of negative polarity and low scalar value serves the purpose of emphasis, while the combination of negative polarity and high scalar value serves the purpose of attenuation. These effects are illustrated by Examples 3 and 5, respectively: if we learn that someone did not attain the smallest unit of sleep we also know that she did not sleep through the night, while a speaker who denies being made of money discloses very little about her true financial status (it might be insolvency if we think the speaker is avoiding an embarrassing admission). For PPIs, the situation is reversed: high scalar values serve to emphasise, while low scalar values attenuate. This is illustrated in Examples 4 and 6, respectively: someone who had a bit of lunch probably (but not certainly) had no more than that, while something that is as big as all outdoors is necessarily also adequately sized.

These observations invite the question: what makes the emphatic PSIs strong and the attenuating ones weak? As argued in detail in the work of Israel $(1996,2011)$, based on foundational work by Fauconnier (1975, 1978), emphasis and attenuation exploit distinct modes of inference. The emphasis strategy relies on scalar entailment, and in particular the evocation of an appropriate scalar model. A scalar model represents a structured set of beliefs about the way the world works. It consists of a set of propositions (containing one or more variables) ordered so as to capture inferential relations among them. For instance, the assertion 'She didn't sleep a wink', as in Example 3, denotes a failure to achieve a minimal unit of sleep, from which we can infer that all propositions involving longer durations do not hold either. Conversely, if the duration were described as 'for days', we would infer that all propositions involving shorter durations also hold. The hyperbolic statement in Example 6 also features this pattern of 'downward entailment': if something is as big as all outdoors, it is also reasonably sized.

The attenuation (or understatement) strategy also relies on scalar inference, but the mechanism is Gricean implicature, not entailment. In an 
affirmative understatement, what is asserted is weaker than a contextually available scalar norm. For instance, 'I ate a bit of lunch', as in Example 4, implies that the amount eaten is less than the default amount imputed to the simple description 'I ate lunch'. This implication arises from the supposition that the speaker is obeying Grice's first maxim of quantity ('Make your contribution as informative as required'): if the speaker had eaten something more than a bit, she would say so. In a negative understatement, what is asserted is less informative than what is implied, because what is asserted involves an extreme that is not actually considered. Example 5, for example, does not merely deny that the speaker is extremely wealthy: its import is rather to deny that the speaker is wealthy at all. This implication arises from the patent violation of the first maxim of quantity: an otherwise cooperative speaker's decision to say something less informative than, say, 'We're not well off', implies that this speaker wishes to avoid discussing her straitened circumstances.

Following Israel, we assume that PSIs constitute a 'broad but well-defined class of scalar operators' (Israel, 2011: 79). Scalar operators belong to the class of contextual operators: lexical items and grammatical constructions whose 'semantic value consists, at least in part, of instructions to find in the context a certain kind of information structure and place the information presented by the sentence within that information structure' (Kay, 1997: 159). Not all scalar operators are PSIs, nor are all contextual operators scalar in nature (see Kay, 2008, on respectively). To explain the inferential patterns associated with PSI uses, we require the two key properties of propositions referenced in Table 1: quantitative value ( $q$-value) and informativeness value (i-value). The $q$-value determines an expressed proposition's position within a scalar model, whilst the $i$-value determines the proposition's inferential value with respect to other propositions in the model.

Crucially, lexical expressions can be specified for one or both of these properties. This seems obvious in the case of $q$-values: a scalar word indexes a point on a scale. It is less obvious in the case of $i$-values: the definition of a word does not typically include its rhetorical affordances. But PSIs, like contextual operators more generally, mean what they mean because they evoke a specific context of use; they are akin to discourse connectives - in many cases, relating the proposition in which they are embedded to one already in the context, as in Kay's (1997) analysis of even. The two properties conspire to create polarity sensitivity, as illustrated by Examples 7 to 12 (=examples 38-39 of Israel (2011)).

\section{Positive}

(7) Lewis is very clever.

(8) Lewis is awfully clever.

(9) * Lewis is all that clever. (NPI) 


\section{Negative}

(10) Lewis isn't very clever.

(11) *Lewis isn't awfully clever. (PPI)

(12) Lewis isn't all that clever.

In Examples 7 to 12, the two polarity-sensitive degree expressions awfully and all that are contrasted with the polarity-neutral, and contextually unrestricted very. ${ }^{3}$ Awfully and all that exhibit a high $q$-value in combination with an adjective. Objectively, they mean more or less the same thing. They differ, however, in their $i$-values. While awfully occurs in statements having a high $i$-value, all that occurs in statements having a low $i$-value. When the context fails to match these items' $i$-value, they are infelicitous $(9 ; 11)$. For most PSIs, $q$-value is a prominent feature of their semantic content (absolutely and $a$ wink).

For the purposes of examining PSIs, it is sufficient to treat $q$-value as a binary opposition: propositions above the scalar norm have high $q$-values and propositions below it have low $q$-values.

The $i$-value of a proposition within a scalar model depends on the number of entailments it has: the more entailments, the higher the $i$ value. If an expressed proposition entails the scalar norm (as eating 'a ton' entails eating a normal amount), then it is more informative than expected (emphatic) and so has a high $i$-value. If the expressed proposition is entailed by the scalar norm (as an average degree of significance entails 'being better than nothing'), it is less informative (attenuating) and has a low $i$-value.

The simple taxonomy of PSIs in Table 1 is, however, insufficient to account for all conventional PSIs. Two sorts of unexpected PSIs, which we will refer to as 'inverted PSIs', disturb this picture. These are illustrated in Examples 13 and 14:

(13) ... wild horses would not make me read such books myself.

(14) I would go back there at the drop of a hat.

Example 13 illustrates an emphatic maximising PSI $[+q,+\mathrm{i}]$ : it denies that even overwhelming force can overcome the speaker's refusal to act. For its part, Example 14 represents an emphatic minimising PSI $[-\mathrm{q},+\mathrm{i}]$ : it asserts the speaker's eagerness to act by asserting her willingness to heed the subtlest signal to act. These particular value combinations would lead us to incorrectly predict that Example 13 should exhibit positive polarity and Example 14 negative polarity. In other words, the taxonomy in Table 1

\footnotetext{
3 The starred Example 11 reflects American English use and judgment. While uses like that found in Example 11 are in fact found, for instance, in the Corpus of Contemporary American English, they are significantly rarer there compared to the British National Corpus (Fisher's exact test, $p=0.0430$ ).
} 
appears too restrictive: 'wild horses' is an emphatic, maximising NPI and 'at the drop of a hat' an emphatic, minimising PPI. Given these additional PSI types, we can no longer treat the polarity of PSIs as arising directly from their scalar features. For instance, the feature combination $[+q,+i]$ now characterises both emphatic maximising PPIs and emphatic maximising NPIs, rather than just the former.

Israel (2011) suggests a motivation for the existence of inverted PSIs, observing a consistent correlation between the sorts of syntactic and semantic roles a polarity item plays within a predication and its status as inverted or canonical. While canonical PSIs tend to express patient-like roles, which are close to the bottom of a thematic-role hierarchy (or to the end of a causal chain), inverted PSIs tend to refer to roles at the opposite (agentive) end. For instance, the 'finger' of 'lift a finger', an emphatic minimising NPI, is a theme, whereas 'wild horses', an emphatic maximising NPI, represents a causal force. The causal force need not be animate: consider the NPI 'for all the tea in China', referenced in the song lyric quoted in Section 1. This item qualifies as an inverted NPI because it is a high-quantity expression used in emphatic utterances. It too obeys the generalisation because, construed as a reward or recompense, the 'tea in China' represents a causal force that compels an otherwise unwilling actor to act.

While we do not yet know whether this generalisation accounts for all patterns of PSI use, the proposal that PSIs systematically occupy certain semantic roles opens up new research questions. For example, it might be beneficial to characterise emphatic minimising NPIs by semantic role rather than grammatical function. This move would lead one to predict the existence of grammatical subjects that are NPIs, since we know independently that English subjects may be undergoer arguments. In fact, such NPIs exist, as illustrated by Example 15, where the incremental theme 'butter' is the subject of the unaccusative verb melt.

\section{(15) I don't have a clue as I am a total innocent and butter would not melt in my mouth.}

In order to begin to test the efficacy of a role-based approach to PSI-types, we will investigate PSIs in the context of Frame Semantics, and the FrameNet resource in particular (Baker et al., 1998). This allows us to use FrameNet frames and frame relations to identify both additional PSI candidates and expressions used in scalar rhetoric even if not conventionalised. Further, this approach allows us to account for divergent behaviours of items within the PSI classes identified by Israel: among these items are those denoting degrees of aversion and attraction and those denoting monetary units. Note that FrameNet does not currently include any information about PSI status. Thus, creating a comprehensive inventory of PSIs would be of lexicographic value. In addition, PSIs are useful for applications from sentiment detection to opinion inference (e.g., Wiebe and Deng, 2014). 
To explore the application of frames and semantic roles to the study of PSIs, we will examine the frames of the PSI expressions themselves, as well as the frames of their governing predicates. The data selected reflect the formal heterogeneity of PSIs. In Section 4 we examine predicative PSIs while in Section 5 we examine PSIs expressed as arguments. But first we briefly discuss the foundations of Frame Semantics.

\section{Frame Semantics}

The central tenet of Frame Semantics is that word meanings are best analysed in terms of experience-based schematisations of events and objects in the speaker's world. Such schematisations, or frames, concern particular types of events and the participants and circumstances that they involve. Individual word senses are called 'lexical units' (LUs). A well-known example is the commercial event frame, which describes a form of bi-directional transfer involving a buyer, a seller, goods and currency. Semantically related words tend to share a single frame. When a LU-the verb buy, for instance-is related to a given frame, that LU is said to 'evoke' that frame. The roles associated with the event are referred to as 'frame elements' (FEs).

FrameNet analyses apply equally to events, relations, states and objects; frame-evoking expressions may be single words or multi-word expressions, and they may be of any syntactic category (Fillmore et al., 2003). As an example, consider the Compliance frame, which is evoked by several semantically related words including adhere, adherence, comply, compliant and violate, among others. Example 16 presents a labelled token, where the Compliance frame is evoked by the verb conform (the 'target' LU).

(16) [You PROTAGONIST] agree to [conform Compliance] [to the terms of the policy NORM] when issued.

The FE Norm identifies the standards to which the Protagonist may or may not adhere. The FE Protagonist refers to the person whose compliance is at issue. The FE Act identifies an action of the Protagonist that is judged either to adhere or violate the Norm. Finally, the FE State_of_Affairs refers to a situation that may violate a norm.

Certain syntactic and interpretive properties follow from a given LU's membership in a particular frame or a given argument's identification with a given FE, and these effects make frame-semantic analysis a useful predictive tool. For example, Ruppenhofer and Michaelis (2014) suggest that the construal of a null-instantiated argument (as definite/anaphoric or indefinite/existential) can be predicted from the LU's frame membership and the FE that the null argument represents. Here we suggest that an expression's frame-semantic properties can also help us to predict its polarity sensitivity, licensing context and inversion potential, as well as certain combinatory 


\begin{tabular}{|l|l|}
\hline 'must, should, gotta, better V', 'absolutely have to V' & Required_event \\
\hline 'be compelled/led to V' & Causation \\
\hline $\begin{array}{l}\text { 'surely, certainly S', 'there is every likelihood + S', } \\
\text { 'be bound to V' }\end{array}$ & Likelihood \\
\hline 'fully expect + S' & Expectation \\
\hline
\end{tabular}

Table 2: Israel's group 8, 'The potential scale: modal polarity items', emphatic-PPI sub-set.

properties, including whether, for example, the expression's PSI status relies on the presence of modifiers.

\section{Frames evoked by predicative PSIs}

Verb-headed expressions, including 'take no for an answer', 'lift a finger' and 'budge', are prominent in the taxonomy of PSIs types. Here, we briefly explore the predictive and explanatory advantages of a frame-based treatment of predicative PSIs by examining two classes identified by Israel (2011). We first consider those that evoke what Israel calls the 'potential scale'. This scale orders situations according to the likelihood of their realisation. Each point on the scale is associated with a lexical class; for example, modal expressions like 'can possibly' and verb-phrase idioms like 'have a hope/prayer/chance' express the lowest potential for realisation. These expressions are thus predicted to be emphatic NPIs, entailing upward to stronger degrees of potential realisation. That is, they are $[-q,+i]$ expressions, as in 'He doesn't have a chance of winning an election'. We focus, however, on expressions in the emphatic-PPI grouping, $[+q,+i]$, which express the highest degree of likelihood. For example, 'I fully expect that S' entails downward to 'I suspect that S'. Table 2 shows the respective FrameNet frames corresponding to the lexical expressions used by Israel to illustrate the emphatic PPIs on the potential scale.

One potential heuristic advantage of the frame-based approach is that by aligning frames with these expressions, which comprise an otherwise unstructured set, we can discover additional candidate PPIs by testing framemate LUs. Take, for example, the Likelihood frame, which has several additional members - including be sure/liable/bound - that also have emphatic PPI functions, as shown by their incompatibility with negation: 'These items are (?not) sure/liable/bound to sell out early'. A framebased treatment also exposes the contributions of 'maximiser' adverbial expressions like fully and absolutely to a predicator's PPI status. FrameNet treats these adverbial expressions as instances of the Degree FE in multiple frames, including the Required Event frame, where this FE is said to express the degree to which the required event is necessary, the Likelihood frame, where it is viewed as expressing the degree of probability of the event's occurring, and the Expectation frame, where it is said to express the 
Cogniser's degree of belief in the prediction. For those predicators belonging to frames that contain the Degree FE, PPI status is typically traceable to the presence of the maximiser adverb. For example, while 'absolutely have to' is a PPI, unmodified 'have to' is not, as shown by its ability to occur in the scope of negation: 'You don't have to go'. The same holds for most of the LUs in the Expectation frame: Expectation LUs that are not otherwise PPIs becomes PPIs in combination with maximiser adverbs, as in Example 17.

(17) But we absolutely anticipate that these people will be able to deal with questions that arise from the public. [cf. 'We don't anticipate that this will occur'.]

Only when an Expectation LU does not generally welcome degree modification does a maximiser adverb have no apparent effect on the predicator's PPI status. For example, because prediction is not ordinarily seen as a matter of degree (one does not predict something to a greater or lesser extent), the verb predict is a PPI whether or not it is modified by a maximiser adverb:

(18) I (fully) predict he and Nenni will spin a conspiracy theory about ARM $\mathrm{H}$ eating into Intel's market share in servers.

Once we know that maximiser adverbs like absolutely and fully yield PPIs in combination with LUs from those frames that contain the Degree FE, we can predict the behaviour of modal expressions that are not represented in Israel's polarity scale. An example is the Certainty frame. Among its LUs are believe, (be) certain and (be) confident. Note that believe, otherwise a non-PSI, becomes a PPI in combination with the maximiser absolutely:

(19) I absolutely believe that this is going to be a big hit. [cf. 'I don't (?absolutely) believe that this is going to be a big hit.')

We now turn to a second set of predicative PSIs identified by Israel: emphatic NPIs that reference the aversion scale. These are shown in the Table 3, along with their corresponding FrameNet frames.

All expressions in this sub-set represent minimal aversion (abstention) and are thus of the type [-q]. They are emphatic under negation only insofar as they denote ability: the presence of a modal verb denoting ability is crucial to their function as emphatic NPIs. Denial of one's ability to abstain is a strong endorsement of the activity under discussion. For example, someone lacking sufficient self-control to wait for lunch strongly desires lunch. By aligning items in this set with frames, we discover otherwise unexploited structure within this set. This practice again enables us to generate additional candidate items from each frame's LU list, some of which are found only in negative-ability expressions (e.g., 'can't help but' - a Self_control LU). In addition, it illuminates divergent behaviours within the 


\begin{tabular}{|l|l|}
\hline $\begin{array}{l}\text { '(can) stay/keep away from', '(can) escape from', } \\
\text { '(would) hesitate to' }\end{array}$ & Avoiding \\
\hline '(can) resist V-ing' & Repel \\
\hline '(can) resist the temptation to V' & Self_control \\
\hline '(can) stop oneself from V-ing' & \\
\hline '(can) wait to V' & Subsisting \\
\hline '(can) live without V-ing' & Sufficiency \\
\hline '(can) get enough of' & \\
\hline
\end{tabular}

Table 3: Israel's group 13 'The aversion scale: abstentive polarity items', emphatic NPI sub-set.

set. Some modalised abstention expressions lead a double life, serving as expressions of mild antipathy in positive sentences (i.e., as understatements of the type $[-q,-i])$. Someone who claims the ability to 'live without' seeing the latest Star Wars film triggers a quantity-based implicature: by saying something uninformative (her survival obviously does not depend on seeing the film), she implies that she wishes to avoid a more pointed assessment of the film. But it would appear that expressions from the Subsistence frame are unique; LUs from other frames represented in Table 3 lack the bipolar property. For example, none of the following are conventional affirmative understatements: '?I can get enough of his company', '?I can resist seeing that film' and '?I can stop myself from drinking coffee'.

The aversion scale has an antonymic counterpart, the desiderative scale. The presence on the aversion scale of an item like '(can) stay away from', an emphatic $[-\mathrm{q},+\mathrm{i}] \mathrm{NPI}$, allows us to predict that on the desiderative scale there should be a PPI item that conveys an endorsement comparable to that conveyed by a negated expression of ability. And in fact at least one such item exists: '(would) jump at the chance' - an emphatic $[+q,+i]$ PPI.

For complex multi-word PSI expressions, we can discover variants by modifying form types and/or substituting close synonyms. Example 20 shows '(can) help myself/ourselves' is an emphatic NPI that is on a par with '(can) help V-ing'.

(20) Yup, I was on my cellphone and I know I'm not supposed to be, but I can't help myself.

Likewise, corpus data reveal that Israel's entry 'cannot resist the temptation to $\mathrm{V}$ ' is but one sub-type of a more abstract pattern. The forces to resist can be grouped into several clusters: inner impulses (the urge/impulse to), external aesthetic forces (the charms/lure/appeal of) and opportunities (an invitation/opportunity/opening to). 


\begin{tabular}{|l||l|l|}
\hline Corpus & Size & Description \\
\hline \hline BNC & $100 \mathrm{M}$ & $\begin{array}{l}\text { Written and spoken British English, wide range of } \\
\text { sources }\end{array}$ \\
\hline $\mathrm{ukWaC}$ & $2.2 \mathrm{~B}$ & British English web corpus \\
\hline NNTC & $150 \mathrm{M}$ & $\begin{array}{l}\text { US newspapers (NY Times, LA Times, Washington } \\
\text { Post, Wall Street Journal, Reuters) }\end{array}$ \\
\hline
\end{tabular}

Table 4: Corpora used.

\section{Frames embedding argument PSIs: monetary units}

Here we explore PSIs filling semantic roles within the frames of the predicators that license them. We focus on PSIs denoting amounts of money (e.g., 'a red cent' and 'a king's ransom'). As expressions of quantity, monetary-unit NPs provide straightforward examples of scalar inference patterns, and because they are closely associated with conventional scenarios involving commercial activities, cost, rewards and expenditures, they provide good illustrations of the utility of a frame-based approach. One clear advantage of a frame-based perspective is that it brings into focus commonalities among monetary-unit expressions, which grammatical divergences might otherwise obscure; for example, 'for a song' is an oblique expression while its close relative 'a pittance' is a direct object. Our data suggest that monetary-unit PSIs behave as inverted PSIs in the conditions predicted by Israel's causal hypothesis but also that framespecific characteristics can differentiate monetary-unit PSIs of the same taxonomic class (e.g., emphatic minimisers). Different monetary-unit PSIs evoke different perspectives (e.g., that of the buyer versus the seller), represent distinct ranges of FEs (e.g., Earnings versus Assets) and have distinct valences (positive versus negative evaluation).

We analyse instances of the target expressions retrieved from the British National Corpus (BNC; Burnard, 2000), ukWaC (Ferraresi et al., 2008), and the North American Newstext corpus (NNTC; Graff, 1995). Table 4 describes the corpora used.

The majority of instances occur in frames that concern commercial transactions, a domain that has been much-analysed in frame-semantic terms. In FrameNet, the area of commerce is mapped by several intricately structured and inter-related frames, which reflect not only distinct relations but also distinct perspectives on those relations. The relevant set of frames is displayed in Figure 1.

As Figure 1 shows, commercial transactions are analysed as exchanges that involve a pair of transfers: the transfer of the goods and the transfer of the money. Each of these transfers can be seen from two perspectives. The Commerce_buy frame represents the perspective of the Buyer obtaining the Goods, while the Commerce_sell frame represents the 


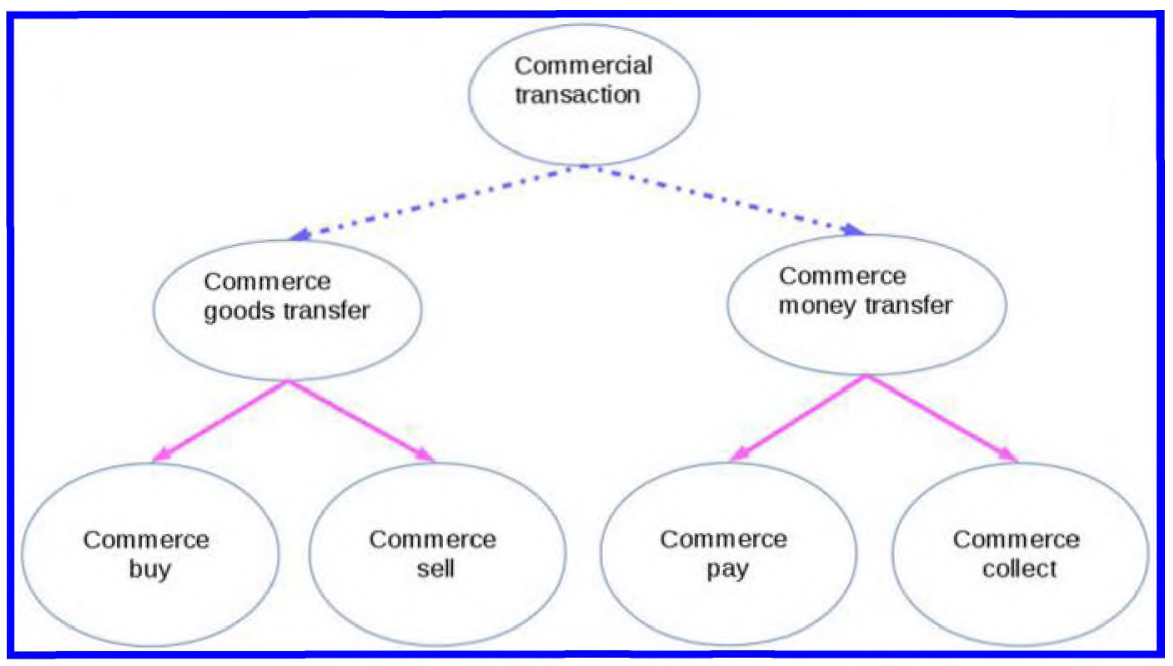

Figure 1: Commerce frames in FrameNet.

perspective of the Seller giving away the Goods. Expressions of money transfer express two parallel perspectives: Commerce_collect represents the perspective of the Seller receiving Money, while Commerce_pay represents the perspective of the Buyer giving Money away to the Seller.

\subsection{Small amounts of money}

We first consider the use of expressions referring to trivial amounts. Examples 21 to 24 illustrate typical uses of two PPIs, 'for a song' and 'a pittance'. In these examples, the commerce frame of the predicator is shown along with the FE label of the particular PPI.

(21) We [buy Commerce_BuY $]$ Third World commodities [for a song MONEY].

(22) And on [the miserable pittance MONEY] you [pay COMMERCE_PAY me, I'm unlikely to amass one.

(23) Jack's only complaint was that [the pittance MONEY] he was [paid COMMERCE_PAY ] hardly reflected the responsibility placed upon him .

(24) While African statues and masks once [went COMMERCE_SELL] [for a song MONEY], ..., this is no longer so.

The distributions of 'for a song' and '(for) a pittance' across different frames in the BNC are shown in Tables 5 and 6, respectively. (In these and subsequent tables, frames posited for this study but not found in FrameNet are marked with an asterisk.) While both expressions appear in a variety of frames, commercial frames predominate. The two phrases pattern with distinct frames. 'For a song' typically fills the role of Money in the Commerce_buy frame, which represents the perspective of a Buyer. Within 


\begin{tabular}{|l||l|l|}
\hline Frame & FE & Count \\
\hline \hline Commerce_buy & Money & 9 \\
\hline Commerce_sell & Money & 9 \\
\hline Exchange* & Theme_2 & 7 \\
\hline Purpose & Purpose & 1 \\
\hline
\end{tabular}

Table 5: FE roles filled by for a song in the BNC.

\begin{tabular}{|l||l|r|}
\hline Frame & FE & Count \\
\hline \hline Small_sum* & Sum & 20 \\
\hline Commerce_pay & Money & 17 \\
\hline Earnings_and_losses & Earnings & 10 \\
\cline { 2 - 3 } Available_resources* & Resources & 7 \\
\hline Exchange & Theme_2 & 4 \\
\hline Grant_permission & Action & 2 \\
\hline Receiving & Theme & 2 \\
\hline Subsisting & Support & 2 \\
\hline Activity_stop & Activity & 1 \\
\hline Cause_motion* & Theme & 1 \\
\hline Cause_to_be_included & New_member & 1 \\
\hline Fining & Fine & 1 \\
\hline Preference & Focal_participant & 1 \\
\hline Respond_to_proposal & Proposal & 1 \\
\hline Retaining & Theme & 1 \\
\hline Sending & Theme & 1 \\
\hline Settling* & Payment & 1 \\
\hline Submit_application* & Request & \\
\hline
\end{tabular}

Table 6: FE roles filled by pittance in the BNC.

that setting, Money is construed as an Instrument-the means by which the transaction is completed. The phrase also occurs frequently in the role of Money in the Commerce_sell frame. This might appear surprising: the phrase appears to represent the buyer's assessment of the transaction (as a bargain) rather than the Seller's. As shown by Examples 25 and 26, however, the apparently anomalous uses typically occur in Commerce_sell predications that represent the perspective of the Buyer. In Example 25, the narrator is the Buyer, and in Example 26, the Seller is backgrounded by the passive construction. 
(25) And he's [letting] it [go COMMERCE_SelL] [for a song MONEY]. Because he's in a hurry. And we're friends.

(26) Eastern Europe also provided an enthusiastic market, as Commodore 64 computers, obsolete in the west, were [sold COMMERCE_SELL] [for a song MONEY] to young people eager for unity and a non-communist identity.

The phrase 'a pittance' typically fills the role of Money in the Commerce_pay frame, which takes the perspective of the Seller. Here the Money is also a causal force-it is the item whose receipt causes the seller to release the goods. The behaviour of both PPIs thus confirms Israel's hypothesis regarding inverted PSIs (see the discussion of 'wild horses' in Section 2). Both 'a pittance' and 'for a song' are inverted PSIs. That is, despite having the value $[-q,+i]$, they are PPIs, not NPIs. In line with this, these expressions, while denoting piddling amounts, $[-\mathrm{q}]$, are used to express highly informative, $[+\mathrm{i}]$, predications, as defined by their entailments. An item that can be purchased for a song or pittance is certainly obtainable for a larger sum.

The foregoing observations suggest that perspectival distinctions are critical to characterising PSIs, and that frames, which encode perspectival distinctions, serve this aim. Buying something for a song usually involves the purchase of items worth more than the amount paid for them. The Buyer (and an external viewer who is sympathetic to the Buyer) will typically approve of such commercial events. Paying a pittance involves the same scenario-paying less for something than it might really be worth, except that the amount paid is signalled to be inappropriately small. This explains, for instance, why first-person referents are much more likely to fill the role of Buyer in the case of 'for a song' than in the case of 'a pittance': saying that one pays somebody else a pittance is self-incriminating. Unsurprisingly, first-person referents are much more likely to fill the role of the Seller who is harmed by the underpayment, as illustrated by Example 22. Example 23 illustrates the same point, as the discourse takes the Seller's point of view.

Other expressions denoting small monetary units function, as expected, as NPIs. One such example is 'a red cent', usually a canonical emphatic minimiser NPI (e.g., 'I didn't have a red cent left'). Since there are no instances of this item in the BNC, we instead look at its occurrences in the ukWaC and NNTC corpora. Table 7 shows figures for both corpora combined.

A speaker describing a small amount of money as 'a red cent' typically evokes a scenario in which a potential Buyer is unwilling to expend even minimal resources for a potential reward; the reward is thereby implied to be unattractive or worthless. Examples illustrating this are presented in Examples 27 and 28. 


\begin{tabular}{|l||l|r|}
\hline Frame & FE & Count \\
\hline \hline Commerce_pay & Money & 6 \\
\hline Giving & Theme & 4 \\
\hline Commerce_collect* & Money & 4 \\
\hline Expend_resources & Resources & 2 \\
\hline Arriving* & Theme & 2 \\
\hline Refunding* & Money & 1 \\
\hline Possession & Possession & 1 \\
\hline Offering & Proposal & 1 \\
\hline Monetary_shortfall* & Sum & 1 \\
\hline Getting & Theme & 1 \\
\hline Earnings_and_losses & Earnings & 1 \\
\hline Disbursing* & Sum & 1 \\
\hline Cause_to_be_included* & New_member & 1 \\
\hline Cause_change_position_on_a_scale & Difference & 1 \\
\hline Extorting* & Money & 1 \\
\hline
\end{tabular}

Table 7: FE roles filled by red cent in ukWaC and NNTC.

(27) It's obvious from the dire state of the roads and pavements that Nottingham Council has written Bilborough off and isn't [spending EXPEND_RESOURCES] [a red cent RESOURCES] to keep them up to scratch.

(28) Why do we bother [paying COMMERCE_PAY $]$ [a red cent MONEY] for these failures?

These implications do not attach to all uses of 'a red cent', however. In certain exceptional cases, the potential Seller delivers for free goods or services that the Buyer was willing to pay for. In these scenarios, the Buyer's assessment of both the Goods and the generous Seller is positive, as in Example 29:

(29) These guys didn't [ask for ${ }^{\text {Request }}$ ] [a red cent Message ], so I figured giving them a big-up on Yelp would be the least I could do.

In the previous examples, the nominal expression 'red cent' functions as an emphatic NPI: it is licensed by overt or implicit negation, as in a rhetorical question that invites a negative response (Example 28). However, 
the expression also occurs, with a distinct array of determiners, in positive contexts:

(30) I will courteously refund [every red cent MONEY] you [paid COMMERCE_PAY ].

(31) There was always the risk people would be "charitied out" and have already [donated GIvING] [their last red cent THEME] to worthwhile causes.

(32) Make 'em [pay COMMERCE_PAY] [every last red cent MONEY] including interest.

In these uses, the phrase is not an NPI. In Example 32, 'red cent' occurs as a part of a larger phrase, 'every last $+\mathrm{N}$ ', that is listed as a PPI by Israel. 'Last $+\mathrm{N}$ ', by itself, may also be a PPI, as suggested by Examples 33 and 34 .

(33) damn i would [give ${ }^{\text {Giving }}$ ] [the last trousers THEME] for this shit with mastering and quality.

(34) He browsed in the second-hand book-shops along Cornhill; and would [spend EXPEND_RESOURCES] [his last cent RESOURCES] for books, apparatus, and supplies.

A distinct positive use of 'red cent', and one that is potentially more interesting from a theoretical perspective, is illustrated by Example 35.

(35) In the city where money is God you can get killed [for ${ }^{\text {ExCHANGE }}$ ] [a red cent ${ }^{\text {THEME_}}{ }^{2}$ ].

Here, for $a$ 'red cent' is used as a non-canonical maximising PPI, akin to 'for peanuts', as in Example 36.

(36) We were in Guatemala last july and people in ciudad guatemala told us "here a life is worth nothing, poverty is high, so is drugs, you can get killed [for ${ }^{\text {EXCHANGE }}$ ] [peanuts ${ }^{\text {THEME_2 }}$ ]".

In cases like Example 35, the monetary expression figures as a reward to be gained, not a resource to be spent. Such uses are rare. The example was in fact retrieved from the web; no instance of this type occurs in the ukWaC or NNTC corpora. But the existence of such uses provides additional support for Israel's hypothesis concerning inverted PSIs (i.e., that inverted PSIs denote causal forces). In contexts like Examples 35 and 36, 'for a red cent' and 'for peanuts' represent inverted PSIs: they are emphatic minimisers of the type $[-q,+i]$, although they occur in positive, rather than negative contexts. These expressions are licit exceptions: they denote an anticipated reward that provides an inducement to act. 


\begin{tabular}{|l||l|l|r|}
\hline Frame & FE & PSI type & Count \\
\hline \hline Commerce_pay & Money & PPI & 4 \\
\hline Large sum* & Sum* & PPI & 3 \\
\hline Commerce_sell & Money & PPI & 1 \\
\hline Containing & Contents & PPI & 1 \\
\hline Expensiveness & Asset & PPI & 1 \\
\hline Giving & Theme & PPI & 1 \\
\hline Labelling & Label & PPI & 1 \\
\hline Attempt_suasion & Content & NPI & 1 \\
\hline Commitment & Message & NPI & 1 \\
\hline Exchange & Theme_2 & NPI & 1 \\
\hline Respond_to_proposal & Proposal & NPI & 1 \\
\hline
\end{tabular}

Table 8: FE roles filled by 'king's ransom' in the BNC

\subsection{Large amounts of money}

We now consider two PSIs denoting large amounts of money, '(for) a king's ransom' and 'an arm and a leg'. We begin with the canonical use of 'king's ransom', exemplified in Example 37. Here, the phrase fills the role of Money in the Commerce_pay frame, which reflects the Buyer's perspective. The expression functions as a canonical emphatic maximising PPI.

(37) But sometimes I want to be pampered like royalty - without having to [pay ${ }^{\text {COMMERCE_PAY }}$ [ [a king's ransom MONEY].

The phrase fills a range of other FE roles, shown in Table 8.

As Table 8 shows, the phrase occurs most frequently as the Money paid in instances of the Commerce_pay frame. In addition it is found in related frames like Commerce_sell and Expensiveness. Surprisingly, a minor use exists in which the expression serves as an NPI, as shown by Examples 38 and 39.

(38) But these days [not even a king's ransom CONTENT] would [tempt ${ }^{\text {ATTEMPT_SUASION }}$ 'Arry to ditch Yorkshire and return to the bright lights of London.

(39) Well, not [for ExCHANGE] [a king's ransom THEME 2] would she return to the kitchen ...

The above uses are emphatic and maximising, just like the primary uses. The difference is that here they are NPIs (i.e., inverted PSIs). This difference 
correlates with a difference in perspective. While the canonical use in Example 37 reflects the Buyer's perspective, those in Examples 38 and 39 reflect the Seller's perspective. Again, these two uses have distinct overtones. The canonical uses involve situations that are negative for the Buyer, who must expend excessive resources to achieve an acquisitive goal. The noncanonical uses also involve situations that are negative for the potential Buyer, but for a different reason: the potential Seller cannot be moved to provide the sought-after good or service.

The minority use of king's ransom suggests that the large-quantity semantics of the item is compatible with two very different reasoning schemes. The expression can either fill the role of a large resource that, from the Buyer's point of view, has to be expended to consummate a deal, or it can serve as a causal force that fails to convince the Seller to sell. In the latter case, as per Israel's hypothesis, the expression represents an inverted PSI: in contexts like Examples 38 and 39, 'a king's ransom' represents a [+q,+i] NPI rather than a PPI, despite what this value combination predicts.

Like the NPI 'red cent', the PPI a 'king's ransom' is found in variant forms, as in Examples 40 and 41.

(40) When we returned to Rome in the winter, I had to [pay COMMERCE_PAY ] [an emperor's ransom MONEY] to import beer from Vesontio.

(41) Dozens of art dealers, foreign and Russian, would [pay COMMERCE_PAY $]$ [a Czar's ransom MONEY] for the Hospital Collection.

Such passages are playful not merely because they contain novel PSIs ('an emperor's ransom' and 'a Czar's ransom') but also because the author tailors the PSI to the particular social/cultural/historical frame evoked (e.g., 'an emperor's ransom' in a passage about Rome).

Some PSIs denoting large monetary units come from nominal expressions that do not intrinsically denote sums, but rather indispensable possessions, including body parts ('my eye teeth') and kin ('my first born'). A conventionalised expression of this nature is 'an arm and a leg', which is ordinarily an emphatic maximising PPI akin to a 'king's ransom'. Examples Examples 42 and 43 illustrate this use.

(42) Oh it's [cost ${ }^{\text {Expensiveness }}$ [ [an arm and a leg AsSET ]!

(43) Well not unless you want to [pay CoMMERCE_PAY $]$ [an arm and a leg MONEY] for them no.

The thirty-one instances of the phrase 'an arm and a leg' that occur in the $\mathrm{BNC}$ are used predominantly in their idiomatic sense. They fill the frame element roles shown in Table 9. 


\begin{tabular}{|l||l|r|}
\hline Frame & FE & Count \\
\hline \hline Expensiveness & Asset & 16 \\
\hline Commerce_pay & Money & 5 \\
\hline Giving & Theme & 2 \\
\hline Expend_resources & Resources & 1 \\
\hline *Saving & *Resources & 1 \\
\hline *Large_sum & *Sum & 4 \\
\hline Literal uses & N/A & 2 \\
\hline
\end{tabular}

Table 9: FE roles filled by 'an arm and a leg' in the BNC (all PPI)

Clearly, the attested frames cast the phrase as a sum of money that a Buyer hands over in exchange for Goods. This context is presupposed even in uses where somebody directly comments only on the size of the sum:

(44) Bloody hell! It must, it must have been absolute [arm and a leg $\left.{ }^{\text {LARGE_SUM }}\right]$.

Although it is not attested in the BNC, 'an arm and a leg', like 'king's ransom', has a minor use as an emphatic maximising NPI (i.e., as an inverted PSI).

(45) I could by a term life insurance policy that would cover me for five years, and if I were 21, it would be very, very cheap, assuming I'm not involved in any high-risk behavior, like flipping the bird to strangers. If I was 91, well, let's just say [an arm and a leg OFFSET*] wouldn't begin to [cover OFFSET_COST*'] it.

(46) I payed [sic] a lot of money about 15 years ago for it..use it everyday and I wouldn't [sell COMMERCE_SELL] it [for an arm and a leg MONEY]!!

Examples 45 and 46 are instances of the ineffectual-causation reasoning that is typical for inverted emphatic maximising NPIs.

Three lessons can be drawn from the study of monetary-unit PSIs. First, PSIs denoting the same objective quantity (e.g., piddling amounts, as in 'a pittance', 'a song' and 'a red cent') may evoke distinct perspectives on the exchange, as well as distinct valuations (e.g., disapproval of a stingy seller who offers a pittance or admiration for a clever buyer who obtains something for a song). Second, PSIs denoting objectively identical amounts, and even one and the same PSI, may serve distinct patterns of inference. Recall that both 'an arm and a leg' and 'a king's ransom' lead double lives as both PPIs and (inverted) NPIs. Such examples show that a given PSI may be classifiable only in a frame-semantic context. Third, when characterising PSIs we must 
look to the internal structure of the expressions, as, for example, 'a red cent' inhabits a distinct licensing context (negative) from that inhabited by 'every red cent' or 'my last red cent' (positive).

\section{Constructing PSIs from comparison constructions}

The findings reported in Sections 4 and 5 suggest that frames and semantic roles are useful for the analysis of PSIs. By mapping previously identified PSIs and PSI classes to frames and frame elements we can discover new PSI candidates and variants (e.g., 'would jump at', 'can live without' and 'a queen's ransom'). In the case of role-filler PSIs, such mappings may expose subtle differences between items that share lexical-semantic content but evoke distinct perspectives (e.g., 'for peanuts' and 'for a pittance'). In addition, by attending to subtle lexical-semantic factors, we can resolve polarity-sensitive words and constructions into their component parts; as we have seen, adverbial expressions, modal verbs and quantifiers can all contribute to a PSI's licensing behaviour. The lesson is that a given PSI may be characterisable as, for example, an emphatic maximiser, only in context. To expatiate upon this point, we turn to a class of non-veridical acts distinct from acts of denial: acts of comparison. Despite representing nonveridical contexts, comparative predications constitute polarity contexts only when the range of possible comparisons at issue is very large. Comparative predications evoke comparison frames containing various FEs. While we refer to the comparative patterns in question as constructions, it is important to note that such constructions are construed as lexical classes in lexicalist implementations of Construction Grammar like that assumed here (see Kay and Michaelis, 2012, for discussion). Among the lexemes in these classes is the degree word as, which selects for both a scalar adjective and a comparative phrase introduced by as (Kay and Sag, 2012).

As we will show, an important strategy for creating PSIs is to manipulate the choice of role filler in a comparison construction.

\subsection{Comparisons of equality}

A simple comparison of equality is found in Example 47, where an Entity is compared to a Standard along a Dimension.
[He Evaluee] is as [intelligent Dimension] as [his boss STANDARD].

While expressed by affirmative sentences, the simple equative comparison is not in itself a PPI context, as shown by Example 48.

(48) [He Evaluee] is not as [intelligent Dimension] as [his boss STANDARD]. 
However, affirmative acts of comparison do count as PPI contexts when the NP expressing the Standard contains free-choice any, particularly when further accompanied by adverbial expressions and post-verbal modifiers like ever and in the world, which signal a particularly broad range of comparative standards.

(49) We can/??can't make [software that EVALUEE] is as [smart DIMENSION] as [any human being STANDARD].

(50) We can/??can't make [software that EVALUEE] is as [smart DIMENSION] as [any human being that has ever lived STANDARD].

Since the all-encompassing Standard requires that the Evaluee measure up to the entity that possesses the highest degree of the relevant property, such comparative predications are akin to superlatives (e.g., 'We make the smartest software').

Another way in which a speaker might turn a simple equative comparison into a PPI context is to deny the existence of any entity that measures up to the entity of interest, also yielding a superlative interpretation.

\section{(51) [Nobody EVALUEe] is as [smart DimENSION] as [Harry STANDARD].}

While the Evaluee (nobody) is the subject of the sentence, such sentences are intended to attribute superlative properties to the Standard (Harry). Alongside the correlative 'as ... as' pattern, there are lexical means of expressing acts of negative comparison. Examples 52 and 53 illustrate verbs that take the Evaluee as subject and the Standard as object.

(52) Way back in the 20th century, the motto used to be "[Nobody EVALUEE] beats [Berkeley STANDARD]"...

(53) [Nowhere EVALUEE] can rival [St James' Park STANDARD] on a matchday, it's the city's heartbeat, pulsing with black and white passion.

A parallel pattern involves predicative nouns like peer and equal: a negativepronoun Evaluee is again the subject but in this case the Standard is expressed by a possessor nominal:

(54) [Nobody EVAlueE] is [his STANDARD] peer [in championing classical music DIMENSION]...

The Evaluee need not be overtly mentioned; various lexical units like those in Example 55 can be said to incorporate it:

(55) beyond compare.prep, incomparable.a, matchless.a, nonpareil.a, peerless.a, unequalled.a., unmatched.a, unrivalled.a, without 
compare.prep, without equal.prep, without match.prep, without peer.prep

The frame-based approach offers a straightforward generalisation about polarity sensitivity in equative comparisons: manipulation of the Standard, as when free-choice any is used as determiner (Examples 49 and 50), results in expressions that are PPIs; by contrast, manipulation of the Evaluee, in particular the use of a negative pronoun as Evaluee, yields expressions that are NPIs, as in Examples 52 to 54. This contrast makes sense in light of the value combinations that characterise each usage pattern. Comparative predications containing any and other 'wideners' can be regarded as $[+q,+i]$ predications since the cardinality of the set of Standards is very high $[+q]$. By the same token, comparative predications containing negative Evaluee arguments can be regarded as $[-\mathrm{q},+\mathrm{i}]$ predications, with the set of possible Evaluees having a cardinality of zero [-q]. Accordingly, comparative predications do not conform to a single polarity type. Rather, their appropriate characterisation varies according to the nature of the Standard FE and the nature of the Evaluee FE.

\subsection{Comparisons of inequality}

Comparisons of inequality differ from comparisons of equality in that the former contain a Difference FE - encoded by various expressions of degree and measure (e.g., 'two inches taller'). A simple polarity-neutral comparison of inequality is illustrated in Example 56:

(56) [He Evaluee] was (not) [tall Dimension]er [than the other horses COMPARISON CLASS].

One way to turn a comparison of inequality into an attribution of superlative quality, and thus into a PPI, is to pick a comparison class that is exhaustive (Example 57) or that contains a paragon (Example 58):

(57) [He EvalueE] was [tall DIMENSION]er [than any other horse in the stable COMPARISON CLASS].

(58) A flutist might certainly be amazed at what the organ world calls a flute, since [some of them EVALUEE] are [tall DIMENSION]er [than a house STANDARD ]...

A comparison of inequality may also become polarity-sensitive when the speaker posits an outsize difference between Evaluee and Standard (Example 59), or denies the existence of a difference (Example 60) relative to a paragon Standard:

(59) [It EVALUEe]'s a(n) [infinitely/vastly/far DIFFERENCE] [smart DIMENSION]er, more organic work that ... (emphatic PPI) 
(60) [Rachel Ray STANDARD] has [nothing DIFFERENCE] on [you EVALUEE]! [culinary prowess] (emphatic NPI)

Since denial of difference is minimising while attribution of superlative quality is maximising, predications of the former sort constitute emphatic NPIs while expressions of the latter sort constitute emphatic PPIs.

\subsection{Superlatives}

The emphatic force of superlatives can be strengthened further, either by widening the comparison class, as in Example 61, or by emphasising the Extent to which the Item surpasses the next highest ranking member of the Comparison class, as in Example 62:

(61) She is the [best DIMENSION] [student ITEM] [out of all the ones I've taught COMPARISON CLASS].

(62) Probably the [weirdest DIMENSION] [video ITEM] [by far EXTENT]!

Both strategies yield emphatic PPIs. The general lesson regarding comparative constructions is that $(a)$ these instantiate a variety of frames and $(b)$ manipulations of role fillers will affect the polarity sensitivity of a predication type. Such manipulations include the use of universal quantifiers, which can turn a polarity-neutral expression of equality or inequality into an attribution of superlative quality, and thus a PPI.

\section{Grammatical constraints}

In Section 5, we showed that several of the PPIs denoting large amounts (e.g., 'a king's ransom') have secondary uses as non-canonical, or inverted, NPIs. Given the semantic and rhetorical underpinnings of polarity sensitivity that we assume, following Israel, we should expect to find such secondary uses quite regularly. However, this expectation may not be borne out, owing to grammatical constraints on the relevant expressions. For instance, we would not expect to find a context in which the PPI 'through the nose', illustrated in Example 63, functions as a non-canonical NPI, as in the unattested, ungrammatical sentence (Example 64):

(63) Your only choice is to either pay 'through the nose' for an individual tailor made policy or go without insurance (not advisable, even illegal in some cases).

(64) *Even through the nose could not buy them an insurance policy. [Intended meaning: even an extraordinary sum would be insufficient to effect the purchase.] 
We suggest that 'through the nose' lacks the ability to invert because, as a locative prepositional phrase, it cannot serve as the subject of a sentence (Bresnan, 1994). Although, as we have seen, PPs headed by for-like 'for all the tea in China' and 'for a king's ransom', do serve as non-canonical NPIs, such expressions do have the ability to appear, in non-oblique form, in subject position - as in, for example, 'All the tea in China could not lead you to lie'. We submit that construal of a PSI as a causal force is dependent on the ability of that PSI to appear, without its preposition, in subject position, since subject position is the canonical position for an agent or 'impetus' argument.

Additional, more subtle, grammatical constraints affect the distribution of PSIs. Consider apparently polarity-sensitive expressions denoting expansible intervals. Such expressions permit cancellation of the Gricean 'upper bounding' implicature, as in, for example, 'She stayed for two weeks (if not three)' and 'I haven't seen him in two years (if not three)'. Adverbials expressing expansible intervals contrast with those expressing punctual intervals. Punctual intervals are those which, in combination with a telic verb, mean ' $n$ time units and no more'. Punctual intervals resist cancellation of the upper-bounding implicature: "?She finished the job in two weeks, if not three'. Punctual adverbials do not appear to be polaritysensitive, whereas those denoting expansible intervals do appear to be PSIs, and are analysed as such by Israel (2011:259-60). Within the set of intervaldenoting PSIs in English, we find NPIs of the form in+NP, in which the NP is an indefinite or bare plural that denotes a long interval in combination with a negated existential-perfect predication like 'I haven't been there'. Examples include 'in weeks / ages / (a million) years / a coon's age'. As NPIs, these so-called frame adverbials, are unwelcome in affirmative contexts: *'She has resided in the country in weeks'. We also find PPIs of the form for $+\mathrm{NP}$, including 'for ages' and 'for an eternity'. As PPIs, such expressions, which we refer to as durational adverbials, are unwelcome in non-veridical contexts: '?I doubt that she (has) resided in the country for ages'. However, Examples 65 to 70 show that the contrast between frame adverbials and durational adverbials is more complex still:

(65) You did not visit/have not visited once $\left[\left\{{ }^{*}\right.\right.$ for $/$ in $\}$ two weeks PERIOD OF ITERATIONS].

(66) I (have) visited twice $\left[\left\{f_{\text {for }}\right.\right.$ in $\}$ two weeks PERIOD OF ITERATIONS]].

(67) Noel's revelation that his younger brother now thinks he's Elvis Presley, comes amid speculation that the pair have not actually spoken [ $\{$ for $/$ in $\}$ weeks DURATION], as they tour Europe. (existential perfect)

(68) I have eaten lunch there [ $\left\{\right.$ for $/{ }^{*}$ in $\}$ weeks DURATION]. (existential perfect)

(69) They have been visiting me [ $\left\{\right.$ for $/ *^{*}$ in $\}$ a coon's age DURATION]. (continuative perfect) 
(70) I haven't known him [ $\left\{\right.$ for $/ *^{*}$ in $\}$ years DURATION]. Rather, it's only been a couple of months since we started dating. (continuative perfect)

The patterns observable here defy a strict identification of frame adverbials with NPIs and durational adverbials with PPIs. When a cardinal adverbial like twice is used to number iterations of an event, as in Examples 65 and 66 , only frame adverbials are acceptable, whether the sentence is negative, as in Example 65 or positive, as in Example 66. When non-occurrence within a vague long interval is at issue, as in the present-perfect predication (Example 67), both types of adverbials are acceptable. While this would seem to imply that the present perfect neutralises the distinction between the two types of adverbials, (Example 68) seems to uphold a polaritybased analysis: affirmative existential-perfect predications welcome only durational adverbials. Once we come to the continuative-perfect predications in Examples 69 and 70, however, the polarity division again seems to evaporate: only a durational adverbial can be used to describe the length of a present-contiguous state phase in a continuative-perfect predication, regardless of polarity: Example 70 shows that even in a negative context, in which the writer denies that the relationship is of long duration, a frame adverbial is impossible, although frame adverbials are putatively NPIs.

These examples suggest that frame-semantic and construction-based generalisations cut across the PPI/NPI division. First, they show that when a frame adverbial denotes a period of iterations it is not polarity sensitive, since such frame adverbials are found in both negative (Example 65) and positive (Example 66) predications, to the exclusion of durational adverbials. Second, they suggest that negative existential-perfect predications, as in Example 67, neutralise the putative polarity distinction, since both types of time-span adverbials are welcome in such sentences. Third, they suggest that Israel's PPI analysis of durational adverbials that express long, vague durations applies only to a single, constructional context: continuativeperfect predications, where the frame adverbial is barred. However, Example 70 shows that the frame adverbial is barred regardless of polarity -a fact which, at the very least, fails to substantiate the identification of frame adverbials with NPIs and durational adverbials with PPIs. Overall, these facts suggest that choices in grammatical analysis, including whether or not we merge continuative and existential readings of the English present-perfect construction (Michaelis, 1994), affect the inventory of PSIs. Further, the above data show yet again that some PSIs can be defined only relative to specific constructional contexts.

\section{Related work}

It is illuminating to relate the present effort to prior corpus studies of PSIs. Hoeksema (1994) studied the distribution of three semantic classes of verbs 
and verbal idioms across contexts of affirmation, interrogation, negation, and what he called 'other negation', showing that these behave as semi-NPIs, with a strong tendency to occur in negative contexts. However, the semi-NPI status of several of the verbs discussed would fall away on a FrameNet-style analysis of the relevant word senses. For instance, since FrameNet separates experiencer-subject verbs such as like from experiencer-object verbs such as please, the verb bother would be a true NPI in its experiencer-subject sense and no NPI at all in its experiencer-object sense.

Hoeksema and Rullmann (2001) carried out a corpus study on the Dutch scalar adverbs ook maar and zelfs maar, both roughly meaning 'so much as', in order to tease out the differences between them and their historical development. Qua adverbs, their objects of study, are very different to the items considered here. However, it is noteworthy that, like the present authors, these authors argue for corpus-based study over introspection-based judgments on the use of PSIs.

In the area of computational linguistics, several efforts have been undertaken to extract PSIs from corpora, relying on distributional properties. Lichte and Soehn (2007) use a corpus-based acquisition mechanism to identify NPIs, treating the relation between an NPI and its licensor as a collocational phenomenon and generating a list of candidate NPIs based on the ratio of the item's occurrences in contexts containing a potential licensor to the item's total number of occurrences in the corpus. In follow-up work, Soehn et al. (2010) report on the creation of a database containing NPIs and PPIs from German and Romanian. The items in the database are described with respect to their own syntactic structure as well as their distribution relative to a set of potential licensing contexts.

Fritzinger et al. (2010) describe the extraction of German NPI candidates from corpora using statistical methods to measure the cooccurrence of candidate items with negative contexts. In addition, they use linguistic criteria to determine the level of idiomaticity of the expressions. These include the degree of morphosyntactic fixedness, the degree of diversity when translated and the percentage of trivial translations of the item in question.

The computational linguistic studies that have targeted PSIs thus far have focussed on NPIs, and in particular on the relationship between the licensor of the negative context and the NPI. By contrast, the rolebased approach to PSIs suggests that we must also consider the expression's relationship to, and the identity of, governing predicators, as determined both by the predicator's frame affiliation and the grammatical construction with which that predicator combines.

\section{Conclusion}

Our point of departure was Israel's (2011) observation that polarity constraints arise not only from the lexical semantics of the relevant expression (whether the item is conventionally construed as an 'emphatic 
minimiser' or an 'attenuating maximiser', etc.) but also from the expression's role in event-semantic representation. Inspired by this insight, we have attempted to explain the behaviour of certain PSIs, in particular 'inverted' PSIs, using tools of frame-semantic analysis. The corpus effort described here involved aligning the relevant predicative and argument-role-bearing PSI sets with FrameNet frames, as well as attending to features of the grammatical context, including the grammatical construction used. We have suggested that the characteristic pattern of scalar reasoning associated with a given PSI depends on a variety of factors:

(a) Frame-specific role; for example, PSIs denoting monetary units like 'a small fortune' display distinct polarities according to whether they are construed as earnings or expenditures.

(b) Frame membership; for example, PSIs belonging to the Subsistence frame differ from other members of the class of abstentive NPIs in that they serve also as PPIs.

(c) Grammatical context; for example, modals, adverbs, quantifiers and highly specific constructions like the event-iteration construction influence an item's polarity sensitivity.

Overall, the results of our role-based investigation support Israel's account of PSIs. We found that the role-based approach can predict secondary uses of certain PSIs, using the same mechanism (causal inference) adduced by Israel to account for non-canonical PSIs like 'wild horses'. To our knowledge, such 'bipolar PSIs' have not been identified previously; their existence indicates that the appropriate classification of a given PSI may depend on context. This study further suggests that reference to frames is needed not only to distinguish among the major PSI classes but also to illuminate perspectival and other differences between the items in a given class (e.g., the monetary units 'a pittance' and 'a song').

Additional research efforts are needed to determine whether other known PSI classes are subject to frame-based generalisations. Such efforts cannot be fully automated, because PSI behaviour is word-sense- and role-specific. We do not possess perfect automatic systems for wordsense disambiguation or semantic-role assignment, so manual analysis will continue to be necessary. Frame-semantic analysis can also be applied to the discovery of novel PSIs. Such efforts will involve systematically searching for phrases that are associated with particular FEs in specific frames and determining their distributions relative to positive and negative contexts.

\section{Acknowledgment}

The first author was partially supported by the German Research Foundation (DFG) under grant RU 1873/2-1. 


\section{References}

Baker, C., C.J. Fillmore and J. Lowe. 1998. 'The Berkeley FrameNet Project', COLING-ACL '98: Proceedings of the Conference. Montreal, Canada.

Bresnan, J. 1994. 'Locative inversion and the architecture of universal grammar', Lanquage 70, pp. 72-131.

Burnard, L. 2000. The British National Corpus Users Reference Guide.

Fauconnier, G. 1975. 'Polarity and the Scale Principle' in R.E. Glossman, I.J. San and T.J. Vance (eds) Papers from the Eleventh Meeting of the Chicago Linguistic Society. Chicago: Chicago Linguistics Society.

Fauconnier, G. 1978. 'Implication Reversal in a Natural Language' in F. Guenthner and S. Schmidt (eds) Formal Semantics and Pragmatics for Natural Languages. The Netherlands: Springer.

Ferraresi, A., E. Zanchetta, M. Baroni and S. Bernardini. 2008. 'Introducing and evaluating ukWaC, a very Large Web-derived Corpus of English' in Proceedings of the Fourth Web as Corpus Workshop. Marrakech: ELRA, pp. 47-54.

Fillmore, C.J., R. Lee-Goldman and R. Rhomieux. 2012. 'The Framenet Construction' in H.C. Boas and I.A. Sag (eds) Sign-Based Construction Grammar, pp. 283-99. Stanford: CSLI Publications.

Fillmore, C.J. 1982. 'Frame semantics. In The Linguistic Society of Korea', (ed.) Linguistics in the Morning Calm, pp. 111-37. Seoul: Hanshin Publishing Co.

Fillmore, C.J. 1985. 'Frames and the Semantics of Understanding'. Quaderni di Semantica 6, pp. 222-54.

Fillmore, C.J. and C. Baker. 2009. 'A frames approach to semantic analysis' in B. Heine and H. Narrog (eds) The Oxford Handbook of Linguistic Analysis, pp. 313-39.Oxford: Oxford University Press.

Fillmore, C.J., C.R. Johnson and M.R. Petruck. 2003. 'Background to FrameNet', International Journal of Lexicography 16, pp. 235-50.

Fritzinger, F., F. Richter and M. Weller. 2010. 'Pattern-based extraction of negative polarity items from dependency-parsed text', Language Resources and Evaluation 2010 (LREC 2010).

Giannakidou, A. 2011. 'Positive polarity items and negative polarity items: variation, licensing, and compositionality' in C. Maienborn, K. von Heusinger and P. Portner (eds) Semantics: An International Handbook of Natural Language Meaning. (Second edition.) Berlin: Mouton de Gruyter.

Graff, D. 1995. North American News Text Corpus LDC95T21.

Hoeksema, J. 1994. 'On the grammaticalization of negative polarity items', in S. Gahl, A. Dolbey and C. Johnson (eds) proceedings of the 
Twentieth Annual Meeting of the Berkeley Linguistics Society, pp. 273-82. Berkeley: BLS, Inc.

Hoeksema, J. and H. Rullmann. 2001. 'Scalarity and Polarity' in H. Rullman, J. Hoeksema and T. van der Wouden (eds) Perspectives on Negation and Polarity Items, pp. 129-71. Amsterdam: Benjamins.

Israel, M. 1996. 'Polarity sensitivity as lexical semantics', Linguistics and Philosonhy 19, pp. 619-66.

Israel, M. 2011. The Grammar of Polarity: Pragmatics, Sensitivity, and the Logic of Scales. Cambridge: Cambridge University Press.

Kay, P. 1997. Words and the Grammar of Context. Stanford: CSLI Publications.

Kay, P. 2006. 'Pragmatic aspects of grammatical constructions' in L. Horn and G. Ward (eds) The Handbook of Pragmatics, pp. 675-700. Oxford: Blackwell.

Kay, P. and L. Michaelis. 2012. 'Constructional meaning and compositionality' in C. Maienborn, K. von Heusinger and P. Portner (eds) Semantics: An International Handbook of Natural Language Meaning. Volume 3, pp. 2271-96. Berlin: de Gruyter.

Kay, P. and I. Sag. 2012. 'Cleaning up the big mess: discontinuous dependencies and complex determiners' in H. Boas and I. Sag (eds) Sign-based Construction Grammar, pp. 229-56. Stanford: CSLI Publications.

Krifka, M. 1995. 'The semantics and pragmatics of polarity items', Linguistic Analysis 25, pp. 209-57.

Lichte, T. and J.-P. Soehn. 2007. 'The acquisition and classification of negative polarity items using statistical profiles' in S. Featherston and S. Sternefeld (eds) Roots: Linguistics in Search of its Evidential Base, pp. 249-66. Berlin: Mouton de Gruyter.

Michaelis, L. 1994. 'The ambiguity of the English present perfect', Iournal ofLinquistics 30, pp. 111-57.

Ruppenhofer, J., H.C. Boas and C.F. Baker. 2013. 'The FrameNet approach to relating syntax and semantics' in R.H. Gouws, U. Heid, W. Schweickard and H.E. Wiegand (eds) Dictionaries: An International Encyclopedia of Lexicography, pp. 1320-9. Berlin: De Gruyter.

Ruppenhofer, J., M. Ellsworth, M. Petruck, C. Johnson and J. Scheffczyk. 2010. FrameNet II: Extended Theory and Practice. (Web Publication: http://framenet.icsi.berkeley.edu)

Ruppenhofer, J. and L.A. Michaelis. 2014. 'Frames and the interpretation of omitted arguments in English' in S. Katz-Bourns and L. Myers (eds) Linguistic Perspectives on Structure and Context: Studies in Honor of Knud Lambrecht, pp. 57-86. Amsterdam: Benjamins. 
Soehn, J.-P., B. Trawiński and T. Lichte. 2010. 'Spotting, collecting and documenting negative polarity items', Natural_Language and Linquistic Theory 28, pp. 931-52.

Wiebe, J. and L. Deng. 2014. An Account of Opinion Implicatures, CoRR $\mathrm{abs} / 1404.6491$.

van der Wouden, T. 1994. Negative Contexts. Groningen University dissertation. 